\title{
Development of Miniature Stewart Platform Using TiNiCu Shape-Memory-Alloy Actuators
}

\author{
Alaa AbuZaiter, Ee Leen Ng, Suhail Kazi, and Mohamed Sultan Mohamed Ali \\ Faculty of Electrical Engineering, Universiti Teknologi Malaysia, 81310 Skudai, Johor, Malaysia \\ Correspondence should be addressed to Mohamed Sultan Mohamed Ali; sultan_ali@fke.utm.my
}

Received 19 September 2014; Revised 28 April 2015; Accepted 29 April 2015

Academic Editor: Yan Yang

Copyright ( 2015 Alaa AbuZaiter et al. This is an open access article distributed under the Creative Commons Attribution License, which permits unrestricted use, distribution, and reproduction in any medium, provided the original work is properly cited.

\begin{abstract}
A Stewart platform is a parallel manipulator robot that is able to perform three linear movements, lateral, longitudinal, and vertical, and three rotations, pitch, yaw, and roll. This paper reports a $30 \mathrm{~mm} \times 30 \mathrm{~mm} \times 34 \mathrm{~mm}$ miniscale Stewart platform using TiNiCu shape-memory-alloy (SMA) actuators. The proposed Stewart platform possesses various advantages, such as large actuation force and high robustness with a simple mechanical structure. This Stewart platform uses four SMA actuators and four bias springs and performs a linear $z$-axis movement and tilting motions. The SMA actuators are activated by passing a current through the SMA wires using a heating circuit that generates a pulse width modulation (PWM) signal. This signal is varied to control the level of the displacement and tilting angle of the platform. The tilting direction depends on the SMA actuator that is activated, while all four SMA actuators are activated to achieve the linear $z$-axis movement. Each SMA actuator exerts a maximum force of $0.6 \mathrm{~N}$ at PWM duty cycle of $100 \%$. The fabricated miniature Stewart platform yields a full actuation of $12 \mathrm{~mm}$ in the $z$-axis at $55^{\circ} \mathrm{C}$, with a maximum tilting angle of $30^{\circ}$ in $4 \mathrm{~s}$.
\end{abstract}

\section{Introduction}

Stewart platform is a parallel manipulator robot utilized to control the position of an object. The typical Stewart platform has a platform, a base platform, and six limbs which could provide six degrees of freedom (DOF) illustrated, three linear movements, lateral, longitudinal, and vertical $(x, y, z)$, and three rotations, pitch, yaw, and roll. During the past decades, Stewart platform had attracted attention of many researchers especially those in robotics field [1]. This type of parallel manipulator possesses high load capacity, precise positioning, high rigidity, and reduced sensitivity to certain errors $[2,3]$. One of the promising areas of Stewart platform is in flight simulator [4]. Other potential applications of Stewart platform are biomedical applications including microsurgical tools, for example, ophthalmic microsurgery, coronary artery bypass graft (CABG) surgery, and brain surgery [5], as well as the application in Computer Numerical Controlled (CNC) machine tool structures, for example, electrodischarge machining [6] and radio telescope positioning system [7].

Actuators are mounted end to end on the top and the base platform, respectively. An actuator converts a type of energy to motion for moving or controlling a mechanism. There are many types of actuators implemented in Stewart platform. The current Stewart platform uses conventional actuators, for instance, the hydraulic actuator [4], pneumatic actuator [8], and servo motor [9]. Hydraulic actuator has high power to weight ratio, has a rapid response [10], and can exert a large force. However, this actuator is large in size, fluid leakage may occur, and maintenance cost is expensive. On the other hand, pneumatic actuator provides fast response and clean operation without the need for oil or fluid for actuation. The disadvantages of pneumatic actuator are mostly caused by nonlinear behavior of the system itself. It is not able to give constant speed to control movement of bodies, has low accuracy, and has difficulty in performing at slow speed. Servo motor provides a great variety of advantages over other actuation methods. Most robotic manipulatorlike miniature Stewart platform uses servo motor as the actuator. The advantages of such actuator are that it is light in weight and yet it can yield a relatively large torque at low voltage and only require small workspace and it provides quiet operation compared to other types of actuators. In fact, they could provide a better accuracy and repeatability work 


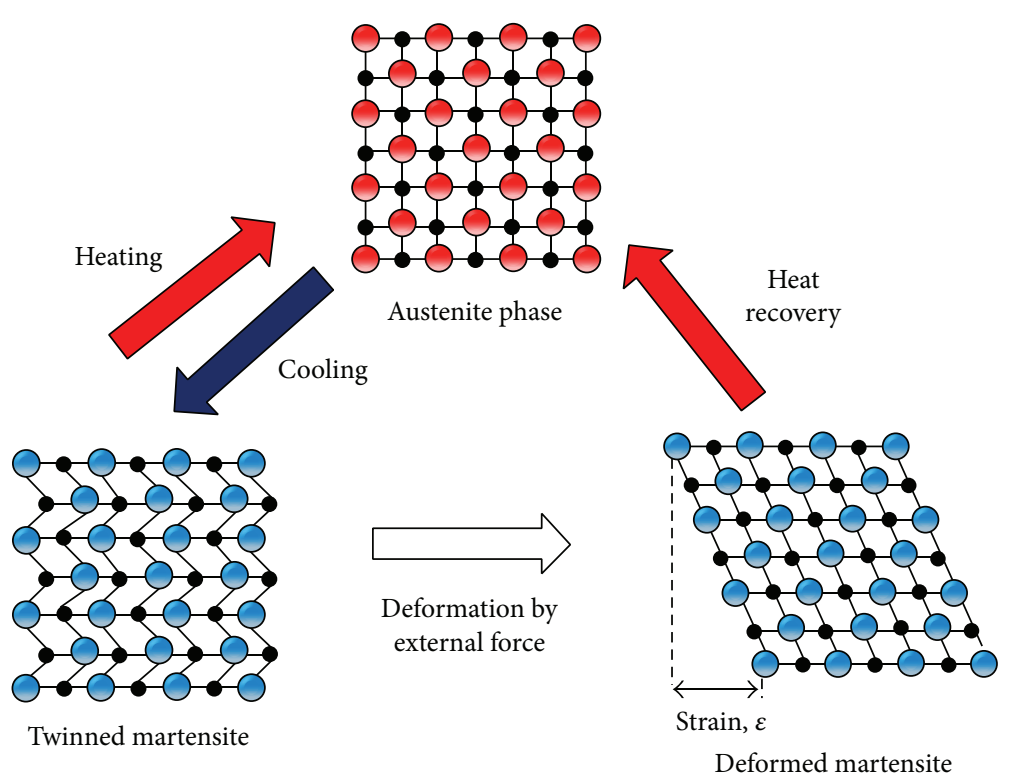

FIGURE 1: SMA phases and crystal structure.

result. However, the cost of this kind of actuator is high. These conventional actuators had made the model become large [11], bulky, and expensive in cost and possess noisy operation. Shape-memory alloy (SMA) that possesses various advantages could potentially solve the issues associated with the conventional actuators especially in the case of Stewart platform.

SMA has been extensively studied in the past few decades due to its uniqueness of "smart" properties. SMA is an alloy, which could remember and return to its original or "remembered" shape when heated [12]. SMA can exist in two different temperature dependent crystal structures (phases) which are low temperature phase called the martensite phase and high temperature phase called the austenite phase [13]. Figure 1 shows the crystal structure in SMA during its phase transformation cycle. At martensite phase, the crystal structure can be easily deformed to a desired shape due to the fact that SMA at this phase has a low yield strength. When SMA is heated above its phase transition temperature indicating it had reached its austenite phase, it will return to its predetermined shape. During this phase, the crystal structure changes to a highly ordered structure and the atomic particles arrange symmetrically. This kind of arrangement possesses high yield strength [14]. The unique behavior of SMA has shown an increased trend in its demands on engineering application in numerous commercial fields such as automotive, biomedical, and robotic field especially as microactuators or artificial muscle $[15,16]$.

Development of Stewart platform using SMA as the actuators has been extensively reported due to the tremendous characteristics of SMA [17-20]. However, they are large in size, involve complicated design, and provide very limited displacement. These factors limit the application range of miniature Stewart platform. In fact, there is also a lack of characterization on the performance of the miniature Stewart platform. For example, the force exerted by the SMA wire, velocity, and dynamic of the moving platform and tilting angles according to the number of Stewart platform's limbs actuated are not well characterized.

This paper reports a miniscale Stewart platform with four DOF. The miniature Stewart platform utilizes SMA microactuators to ensure the device has a high robustness with simple mechanical structure. The device is able to perform linear $z$-axis movement and also tilting motions. Performance characterization of the device is conducted to show the reliability of SMA in the miniature Stewart platform.

\section{Design and Principle Work}

The size of miniature Stewart platform developed in this effort is $30 \mathrm{~mm} \times 30 \mathrm{~mm} \times 34 \mathrm{~mm}$ in dimension with three DOF, two of which enable the Stewart platform to rotate in $x$ and $y$-axis while the third DOF is responsible of moving the platform in $z$-axis as shown in Figure 2. The construction of this device involves a platform, a base platform, and four limbs with identical dimensions. Each limb consists of a bias spring and an SMA actuator (Figure 2).

Figure 3 shows the working principle of miniature Stewart platform. The actuation will be controlled using a user interface from a computer. The computer then connects to a microcontroller. For actuations to take place, the microcontroller will generate a PWM signal to be transmitted into a heating circuit with voltage and current source of $5 \mathrm{~V}$ and $2 \mathrm{~A}$, respectively. This is to ensure a sufficient heat generated on SMA actuator and exceeds the transition temperature of $70^{\circ} \mathrm{C}$ (austenitic phase temperature) for its actuation. The duty cycle of the PWM signal is varied to control the level of actuation in terms of Stewart platform's height displacement and tilting angle. A bias spring stretches the SMA when it is at martensite phase, whereas at austenite phase, SMA 


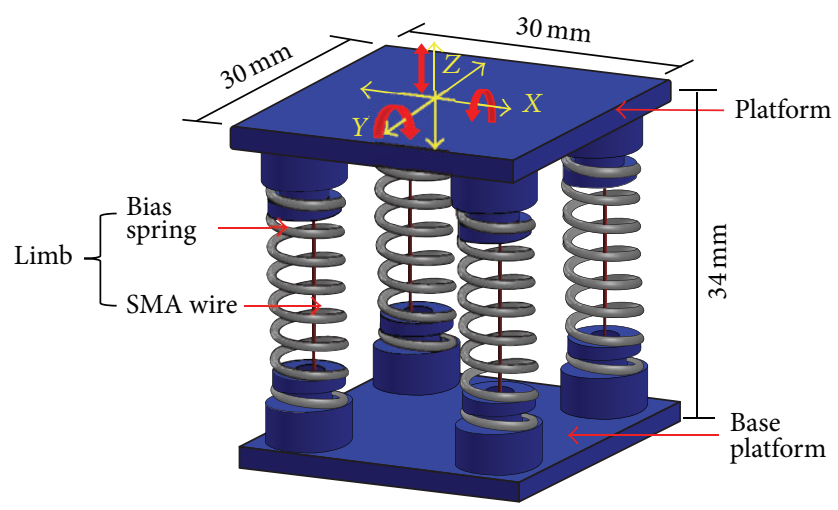

FIgURE 2: Stewart platform design.

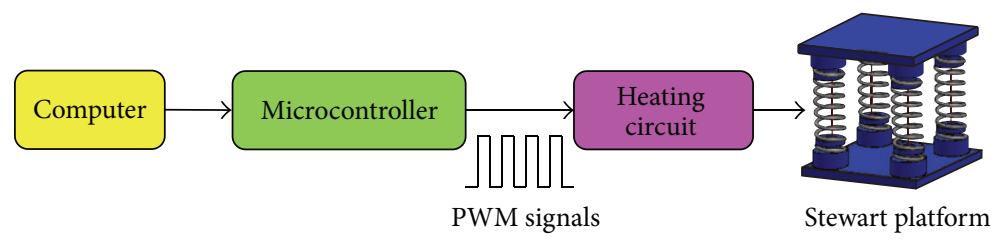

FIGURE 3: Working principle of the Stewart platform.

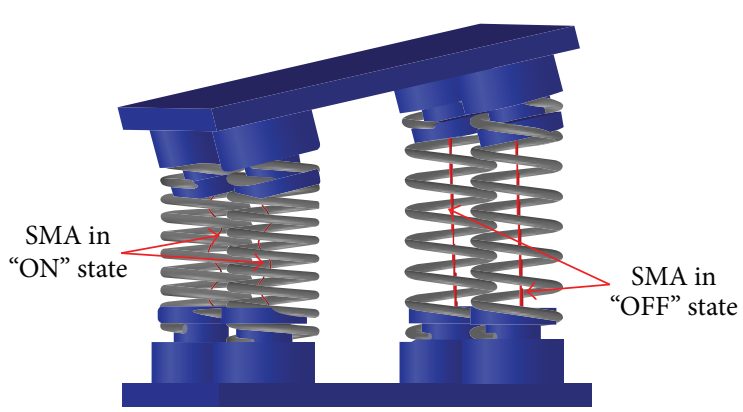

(a)

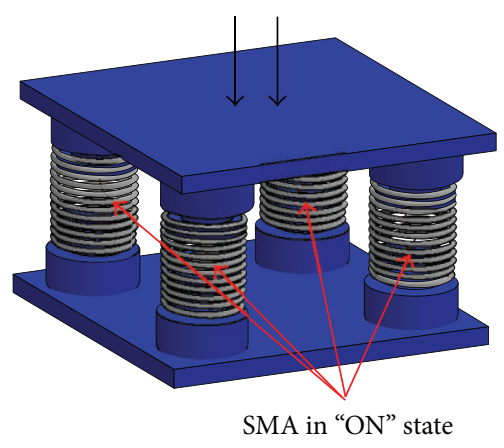

(b)

FIGURE 4: The mobility of developing Stewart platform; (a) tilting effect of Stewart platform; (b) linear $z$-axis movement.

actuator will exert a force which then pulls the platform and compresses the spring. Figure 4 depicts the movement in three DOF of developed design. By actuating one limb or two adjacent limbs simultaneously, two or one rotational DOF around $x$ - and $y$-axis can be achieved, respectively. The tilting direction and its angle depend on which limbs are activated and on the duty cycle of PWM signal (Figure 4(a)) such that the higher the duty cycle, the more the yielded tilt. Furthermore, activating the four limbs leads to the third DOF in the $z$-axis. Similarly, the displacement in the $z$-axis direction is also determined by the duty cycle of PWM signal (Figure 4(b)).

\section{Fabrication}

A TiNiCu type SMA wire (M-type, Memry Corp., Germany) with thickness of $170 \mu \mathrm{m}$ was used as actuator in Stewart platform. The SMA wires were trained to memorize a springlike shape (Figure $5(\mathrm{a})$ ) by annealing at $400^{\circ} \mathrm{C}$ with predefined shape for one hour and then crunching in cold water. Bias springs with an outer diameter of $9.2 \mathrm{~mm}$ with a wire thickness of $0.2 \mathrm{~mm}$ and height of $25 \mathrm{~mm}$ were fabricated (Figure 5(b)). The top and base platforms were designed using $\mathrm{CAD}$ software and fabricated using rapid prototyping process. Then, four limbs each of them consisting of an SMA actuator and a bias spring were attached to the base of the Stewart platform (Figure 6(a)). Both ends of each SMA actuator were connected to the heating circuit using conductive paste. The limbs were then connected to the top platform to form a complete prototype (Figure 6(b)). Screws were used to ensure a firm attachment and connectivity between the SMA wire and wire that connects to the heating circuit. A PWM signal that is generated from a heating circuit is used to control the current flowing in the four SMA microactuators. The microcontroller is connected to the heating circuit to 


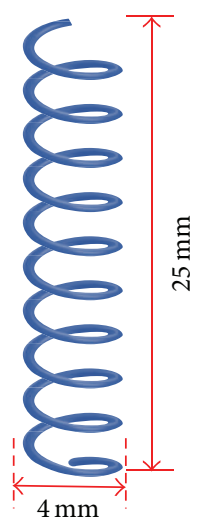

(a)

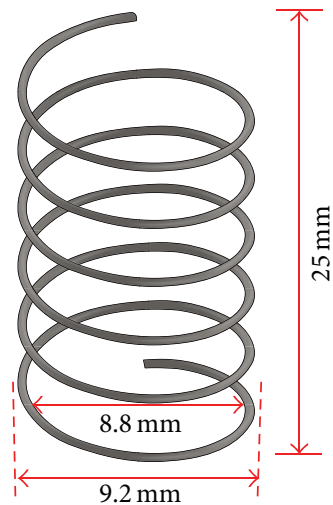

(b)

FIGURE 5: (a) Dimension of SMA spring; (b) bias spring design.

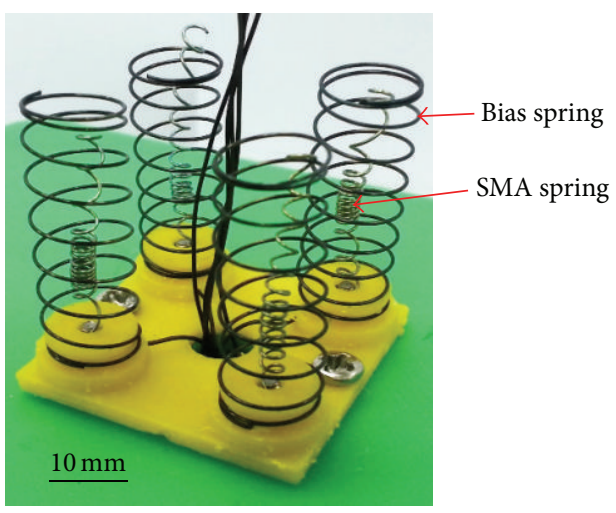

(a)

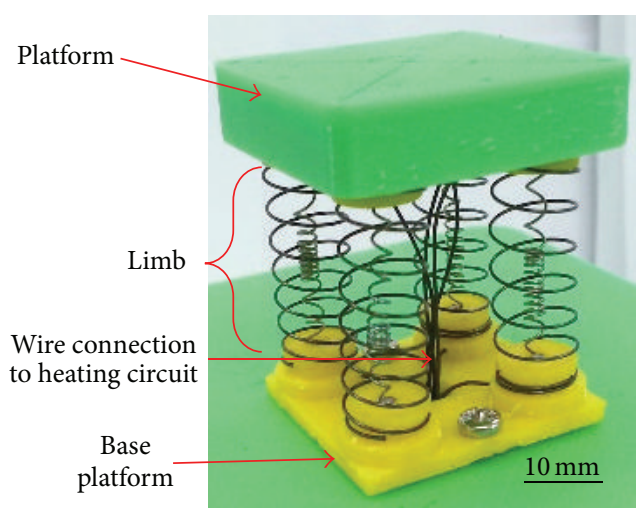

(b)

FIGURE 6: Fabrication results: (a) limbs attached to base platform; (b) complete prototype.

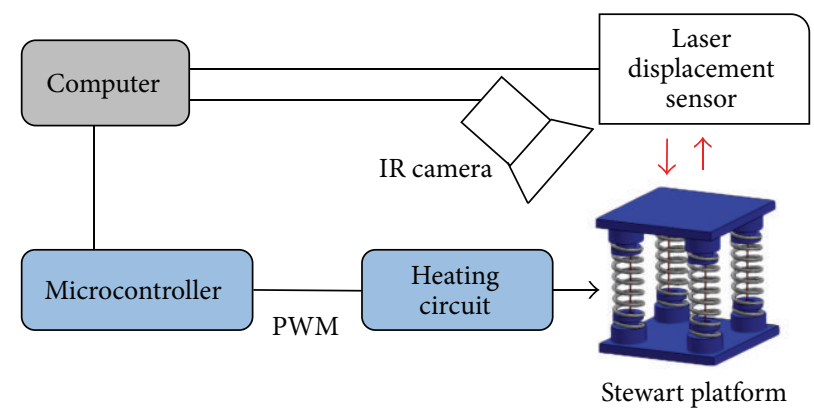

FIGURE 7: Experimental setup for miniature Stewart platform performance characterization.

control the PWM signal which consequently controls the actuation of the SMA microactuators.

\section{Experimental Results and Discussions}

Experimental characterizations for the developed device were performed using setup illustrated in Figure 7. Laser displacement sensor (LK-G32, Keyence, IL, USA) and IR thermal camera (D-07739, Jenoptic, Jena, Germany) were used to measure the displacement range of the Stewart platform and the temperature of SMA actuators, respectively. Force gauge (IPM650, Futek, CA, USA) was used to measure the force exerted by the SMA actuator when it is activated (force gauge not shown in Figure 7).

4.1. Variation of Displacement with Different Values of Duty Cycle. The aim of this experiment is to evaluate the temporal response of SMA actuator with respect to different duty cycle of PWM signals generated from the microcontroller. The measurement process of temporal response for the prototype 


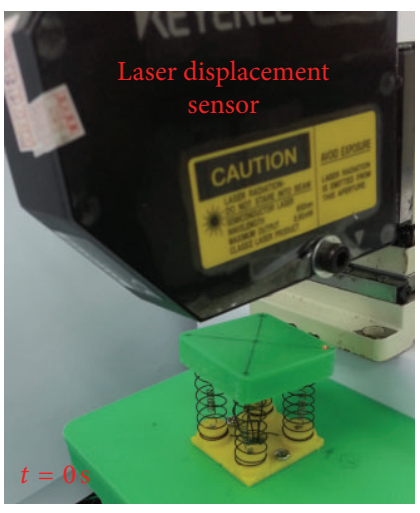

(a)

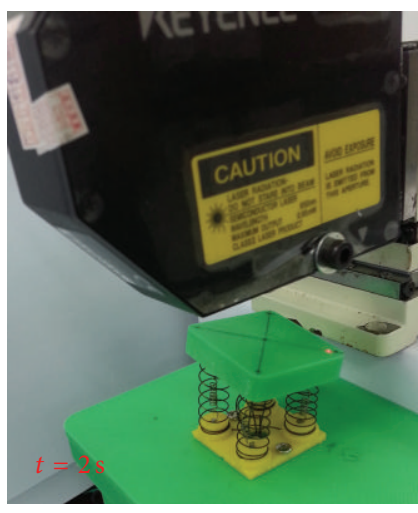

(b)

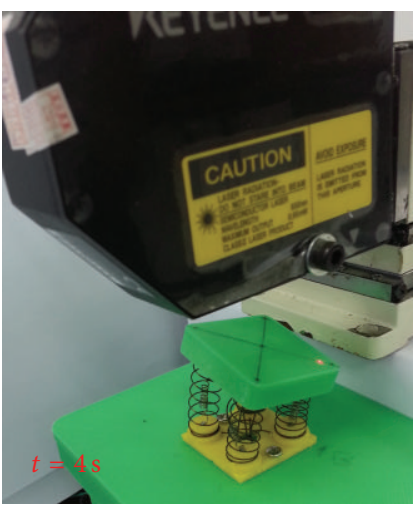

(c)

FIGURE 8: Measurement process of temporal response for miniature Stewart platform prototype at PWM duty cycle of $75 \%$.

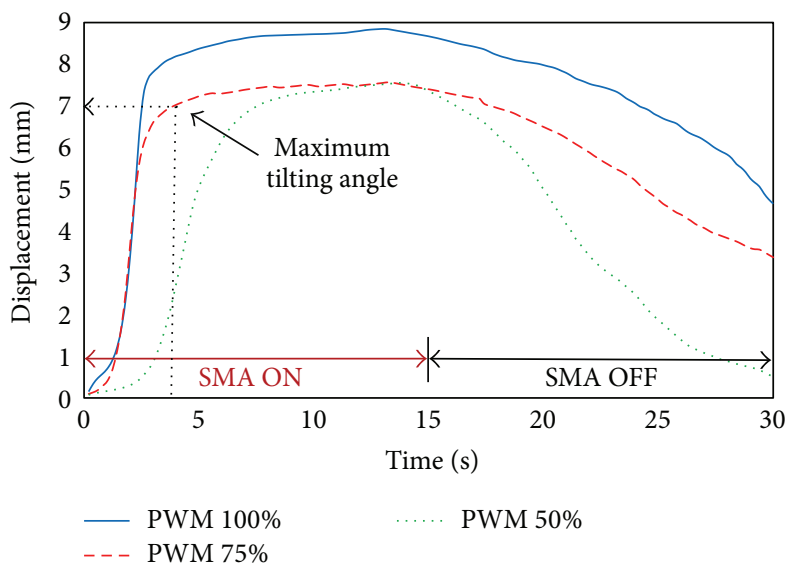

FIGURE 9: Temporal response of SMA actuator with different PWM duty cycles.

is being illustrated in Figure 8. Only one limb's SMA is actuated for this purpose. The SMA will be on (actuated) for $15 \mathrm{~s}$ and off (not actuated) for another $15 \mathrm{~s}$ to ensure a consistency throughout the experiment. The change in displacement was recorded every $200 \mathrm{~ms}$. The experiments are carried out using different values of PWM which consists of duty cycle of $50 \%, 75 \%$, and $100 \%$. A temporal response graph is plotted as shown in Figure 9.

From the graph, it is observed that the time response of SMA actuator to reach its full actuations is $8 \mathrm{~s}, 4 \mathrm{~s}$, and $2.6 \mathrm{~s}$ for duty cycle of $50 \%, 75 \%$, and $100 \%$, respectively. Meanwhile, the temporal response of SMA actuator is $2.519 \mathrm{~mm} / \mathrm{s}$, $4.71 \mathrm{~mm} / \mathrm{s}$, and $6.05 \mathrm{~mm} / \mathrm{s}$ for duty cycle of $50 \%, 75 \%$, and $100 \%$, respectively. The difference in the duty cycle values has an important factor in controlling the actuation speed. As the given duty cycle is higher, the actuation time to reach to the full actuation will become lesser. Maximum displacement of each duty cycle shown in the graph is different due to the fact that the initial values are set differently. From the calculation of initial value added to the displacement value obtained from sensor, the prototype could move to a maximum displacement of $12 \mathrm{~mm}$. It is observed that the miniature Stewart platform prototype is able to tilt up to an angle of $\sim 30^{\circ}$. The results are shown in Figure 10.
4.2. Variation of Temperature with Different Values of Duty Cycle. The aim of this experiment is to determine the actuation temperature (thermal response) of SMA actuator with respect to different duty cycle of a PWM signal. The measurement process of thermal response of SMA actuator is shown in Figure 11. For this experiment, only one SMA actuator is actuated and the change of temperature was recorded every second. As shown in Figure 11, the temperature was increased to $82^{\circ} \mathrm{C}$ in $7 \mathrm{~s}$ and could be varied by tuning the PWM signal. To ensure consistency, the actuation time of SMA is the same as the measurement of temporal response where the actuator was in $\mathrm{ON}$ state for $15 \mathrm{~s}$ and turned off for $15 \mathrm{~s}$. The experiment was carried out using different PWM signal that consists of duty cycle of $50 \%, 75 \%$, and $100 \%$. Experimental results were recorded and graph of the thermal response of SMA actuator is plotted as shown in Figure 12.

The thermal response graph illustrates that the time for SMA actuator to reach its austenite phase with respect to the duty cycle of $50 \%, 75 \%$, and $100 \%$ is $9 \mathrm{~s}, 6 \mathrm{~s}$, and $5 \mathrm{~s}$, respectively. The maximum temperatures at the end of the actuation are $104^{\circ} \mathrm{C}, 142.3^{\circ} \mathrm{C}$, and $162^{\circ} \mathrm{C}$ for duty cycle of $50 \%$, $75 \%$, and $100 \%$, respectively. The difference in maximum temperature is due to the average voltage supplied across the SMA as a result of applying different values of duty 


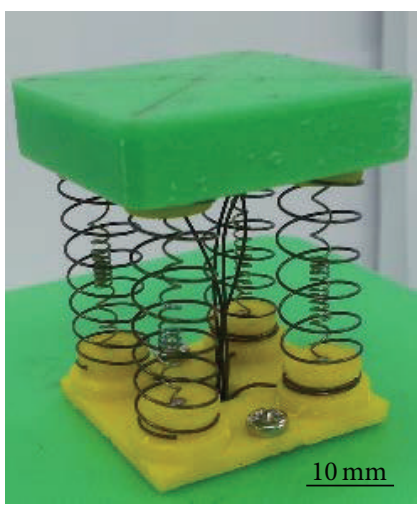

(a)

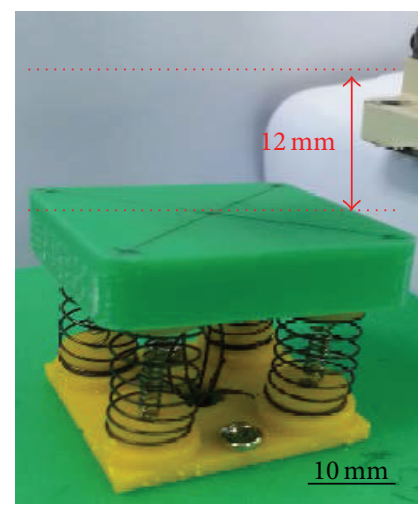

(b)

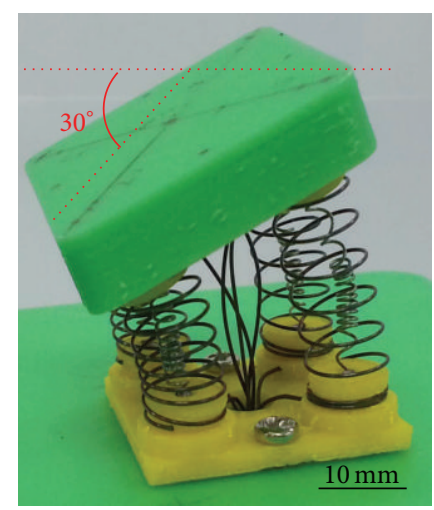

(c)

FIgURe 10: Prototype results: (a) initial state; (b) maximum displacement; (c) tilting angle.

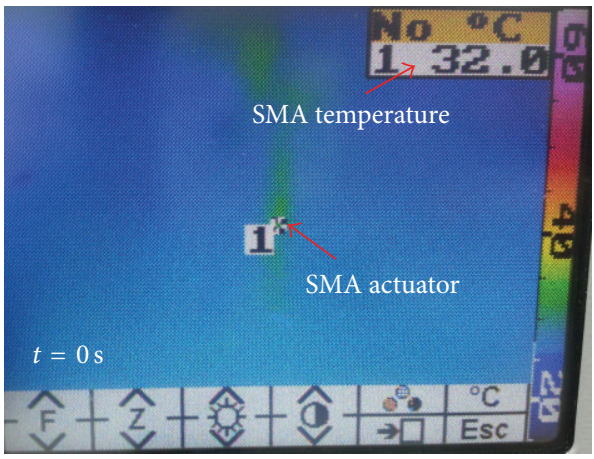

(a)

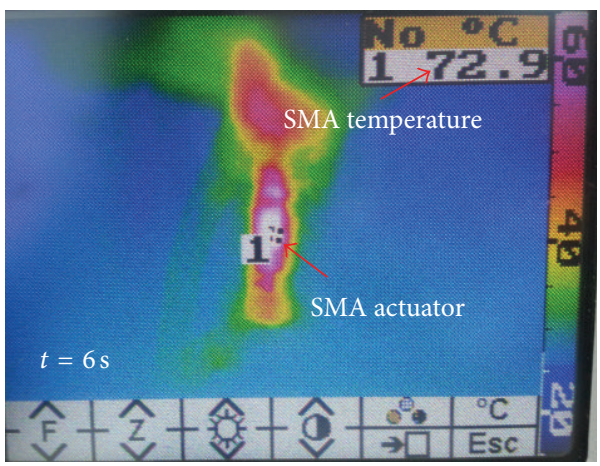

(c)

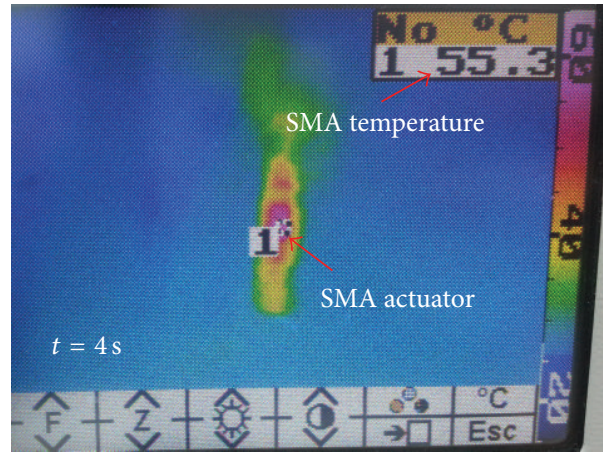

(b)

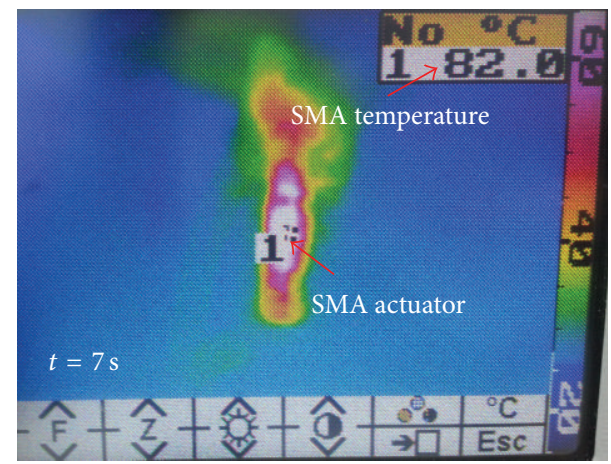

(d)

FIGURE 11: IR image showing transformation of SMA from martensite to austenite phase.

cycle. On the other hand, the higher the temperature is, the faster the response of SMA to transform from martensite to austenite phase is. As for the cooling process, where austenite changes to martensite phase, at the duty cycle of $50 \%$, the SMA actuator took $30 \mathrm{~s}$, whereas at a duty cycle of $75 \%$ and $100 \%$, the SMA actuator took more than $30 \mathrm{~s}$ to reach room temperature. When the SMA actuator reaches martensite phase, it is readily deformed by any external force, which in this case is pulling force exerted by the spring.

4.3. Combination of Temporal Response and Thermal Response of Miniature Stewart Platform. This section discusses the temporal response together with thermal response of the miniature Stewart platform prototype at PWM duty cycle of $75 \%$. The graphs of temporal response and thermal response at duty cycle of $75 \%$ are combined. The fabricated miniature Stewart platform yields a full actuation at $55^{\circ} \mathrm{C}$ and is able to tilt a maximum angle of $30^{\circ}$ in $4 \mathrm{~s}$ with the temporal response of $4.71 \mathrm{~mm} / \mathrm{s}$ when PWM duty cycle is set at $75 \%$ (Figure 13 ).

The developed miniature Stewart platform prototype could perform several motions. When one SMA in the prototype's limbs is actuated, it will exert a force larger than the force in the springs and eventually pulls the platform down to the side where SMA is actuated. This will produce 


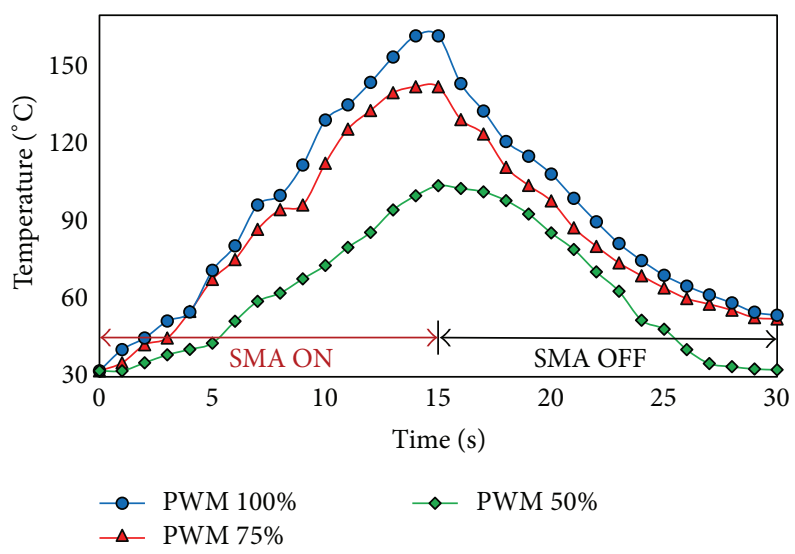

FIGURE 12: Thermal response of SMA actuator with different PWM duty cycles.

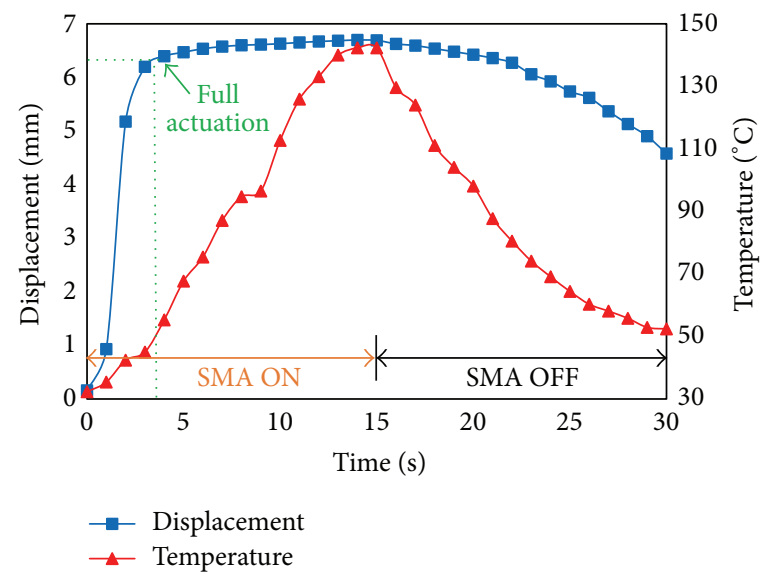

FIGURE 13: Temporal and thermal response of SMA actuator at PWM duty cycle of 75\%.

a tilting effect of the prototype as shown in Figure 14. When the four SMAs of all the limbs are actuated simultaneously, the platform will be pulled by the four SMA actuators and it will produce a linear $z$-axis motion as shown in Figure 15.

4.4. Discussions. The results demonstrated above show the feasibility to develope a Stewart platform, by relatively simple fabrication steps, that has low cost and an easy control method (compared to [21]). Furthermore, the use of SMA actuator, as explained in the introduction, has added up several advantages; it has provided high working density which allowed generating high force compared to other similar platforms such as the platform reported by Estevez et al. [22]. Also, the shape-memorizing ability provided both the required force and the direction to actuate the limbs. Another advantage of developing this design is to achieve three-DOF motion, which is higher than other previous works that utilized SMA in Stewart platform such as the one reported by Hadi et al. [23] which only had two DOF. Besides, the size of this platform was miniaturized while maintaining higher displacement compared to other bigger size SMAbased Stewart platforms $[19,24]$.
The small size feature promotes several possible applications for this platform such as milling machine technology, in biomedical application as microsurgery tools and in robotic systems as end of robotic arm. Moreover, series of this platform can be attached to form flexible robot arm. Last but not least, this design can be used as miniature light or laser beam reflector by attaching mirror to the top platform surface.

\section{Conclusion}

A miniscale Stewart platform that uses four SMA actuators and four bias springs to perform a linear $z$-axis movement and tilting motions was successfully developed and characterized. Each actuator was driven by heating circuit operating via PWM signal for its actuation, with a voltage and current source of $5 \mathrm{~V}$ and $2 \mathrm{~A}$, respectively. The use of PWM signal as a driving signal enables the displacement control without the need for physical modification in the heating circuit. PWM signal was varied to control the level of actuation in terms of the $z$-axis displacement and tilting. Each SMA actuator exerted a maximum force of $0.6 \mathrm{~N}$ at PWM duty cycle of $100 \%$. The fabricated miniature Stewart platform produced a full actuation at $55^{\circ} \mathrm{C}$ and a maximum tilting 


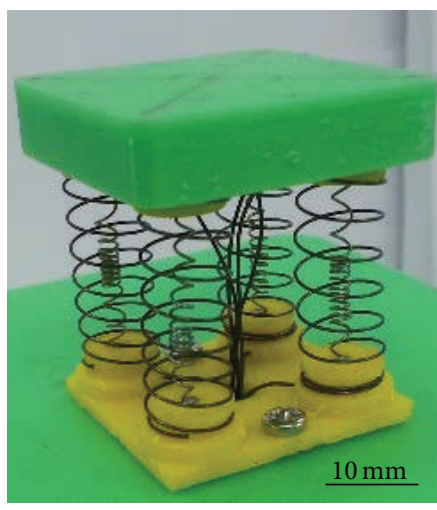

(a)

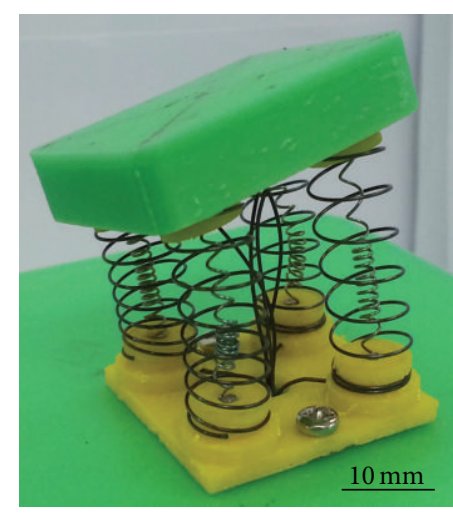

(b)

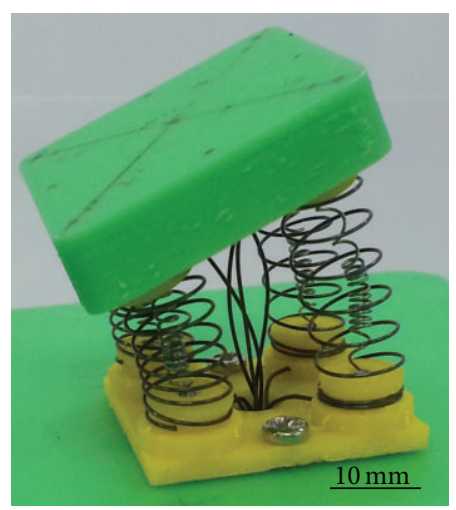

(c)

FIGURE 14: Tilting effect of miniature Stewart platform prototype; (a) initial state; (b) one-limb actuation; (c) two-limb actuation.

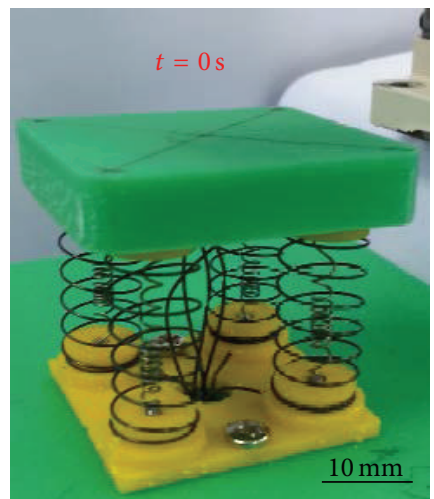

(a)

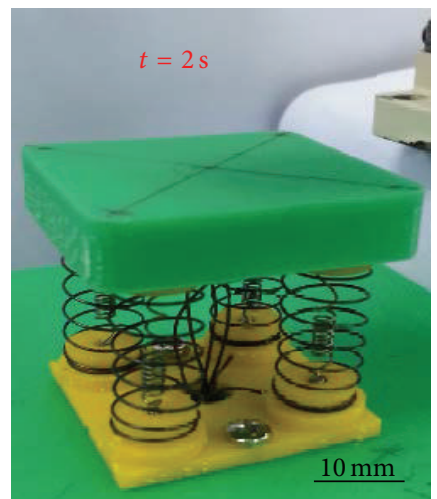

(b)

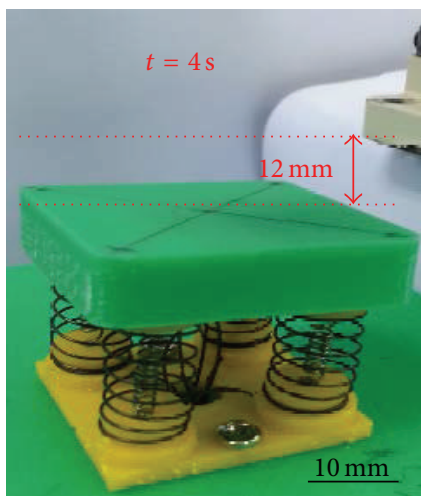

(c)

FIGURE 15: Linear $z$-axis motion height control of miniature Stewart platform prototype; (a) initial state; (b) four-limb actuation $(t=2 \mathrm{~s})$; (c) four-limb actuation $(t=4 \mathrm{~s})$.

angle of $30^{\circ}$ with a temporal response of $4.71 \mathrm{~mm} / \mathrm{s}$, when the PWM duty cycle is set to $75 \%$. The displacement in the $z$-axis has a range of $12 \mathrm{~mm}$. Several future works are expected to be done to improve the performance of the currently developed miniature Stewart platform. This includes improvements of the hardware, such as adding more limbs to achieve more actuation directions and higher DOF. Another critical enhancement is optimizing the response time of the actuator which can be achieved by employing SMA with lower austenitic phase temperature [25, 26]. Additionally, forward and inverse kinematics are also important elements to be explored.

\section{Conflict of Interests}

The authors declare that there is no conflict of interests regarding the publication of this paper.

\section{Acknowledgments}

This work was supported by Ministry of Education Malaysia under Prototype Development Research Grant Scheme (PRGS) and Ministry of Science and Technology Malaysia under E-Science Fund. The authors also thank Brad Bycraft for his assistance in paper preparation.

\section{References}

[1] Z. Huang and Y. Cao, "Property identification of the singularity loci of a class of Gough-Stewart manipulators," The International Journal of Robotics Research, vol. 24, no. 8, pp. 675-685, 2005.

[2] J.-P. Merlet, Parallel Robots, vol. 74, Springer, Berlin, Germany, 2001.

[3] B. Kang, J. Chu, and J. K. Mills, "Design of high speed planar parallel manipulator and multiple simultaneous specification control," in Proceedings of the IEEE International Conference on Robotics and Automation (ICRA '01), pp. 2723-2728, May 2001.

[4] R. S. Stoughton and T. Arai, "Modified Stewart platform manipulator with improved dexterity," IEEE Transactions on Robotics and Automation, vol. 9, no. 2, pp. 166-172, 1993.

[5] K. W. Grace, J. E. Colgate, M. R. Glucksberg, and J. H. Chun, "Six degree of freedom micromanipulator for ophthalmic surgery," in Proceedings of the IEEE International Conference on Robotics and Automation, pp. 630-635, May 1993.

[6] K. Furutani, K. Shibatani, N. Itoh, and N. Mohri, "A parallel link end effector for scanning electrical discharge machining process," Precision Engineering, vol. 22, no. 3, pp. 131-140, 1998. 
[7] J. C. Jáuregui, E. E. Hernández, M. Ceccarelli, C. LópezCajún, and A. García, "Kinematic calibration of precise 6-DOF Stewart platform-type positioning systems for radio telescope applications," Frontiers of Mechanical Engineering, vol. 8, no. 3, pp. 252-260, 2013.

[8] R. Boian, H. Kourtev, K. Erickson, J. Deutsch, J. Lewis, and G. Burdea, "Dual Stewart-platform gait rehabilitation system for individuals post-stroke," in Proceedings of the 2nd International Workshop on Virtual Rehabilitation, Piscataway, NJ, USA, 2003.

[9] N. Ando, P. Korondi, and H. Hashimoto, "Development of micromanipulator and haptic interface for networked micromanipulation," IEEE/ASME Transactions on Mechatronics, vol. 6, no. 4, pp. 417-427, 2001.

[10] M. R. Sirouspour and S. E. Salcudean, "Nonlinear control of hydraulic robots," IEEE Transactions on Robotics and Automation, vol. 17, no. 2, pp. 173-182, 2001.

[11] P. Kallio, M. Lind, H. Kojola, Q. Zhou, and H. Koivo, "An actuation system for parallel link micromanipulators," in Proceedings of the IEEE/RSJ International Conference on Intelligent Robots and Systems (IROS '96), pp. 856-862, 1996.

[12] J. Huang, X. Chen, and L. Zhong, "Analysis and testing of MR shear transmission driven by SMA spring," Advances in Materials Science and Engineering, vol. 2013, Article ID 307207, 6 pages, 2013.

[13] L. L. Meisner, A. I. Lotkov, Y. P. Mironov, and A. A. Neyman, "Evolution of structural-phase states in TiNi surface layers synthesized by electron beam treatment," Journal of Nanotechnology, vol. 2010, Article ID 605362, 8 pages, 2010.

[14] A. Lu, D. Grant, and V. Hayward, "Design and comparison of high strain shape memory alloy actuators," in Proceedings of the IEEE International Conference on Robotics and Automation (ICRA' 97), pp. 260-265, April 1997.

[15] K. J. de Laurentis and C. Mavroidis, "Mechanical design of a shape memory alloy actuated prosthetic hand," Technology and Health Care, vol. 10, no. 2, pp. 91-106, 2002.

[16] J. Ma, H. Huang, and J. Huang, "Characteristics analysis and testing of SMA spring actuator," Advances in Materials Science and Engineering, vol. 2013, Article ID 823594, 7 pages, 2013.

[17] T. Raparelli, P. B. Zobel, and F. Durante, "Design of a parallel robot actuated by shape memory alloy wires," Materials Transactions, vol. 43, no. 5, pp. 1015-1022, 2002.

[18] R. Abiri, M. Kabganian, and R. Nadafi, "Fabrication, modeling and set-point control of a new flexible microrobot module (FMM) by using SMA actuators," in Proceedings of the 1st RSI/ISM International Conference on Robotics and Mechatronics (ICRoM '13), pp. 141-146, February 2013.

[19] A. M. B. S. Roslan, V. Amirtham, T. Nagarajan, and F. M. Hashim, "SMA actuator technology application in Stewart Platform construction," Journal of Applied Sciences, vol. 11, no. 23, pp. 3783-3790, 2011.

[20] M. Sreekumar, M. Singaperumal, T. Nagarajan, M. Zoppi, and R. Molfino, "A compliant miniature parallel manipulator with shape memory alloy actuators," in Proceedings of the IEEE International Conference on Industrial Technology (ICIT '06), pp. 848-853, December 2006.

[21] R. Dunlop and A. C. Garcia, "A nitinol wire actuated stewart platform," in Proceedings of the Australasian Conference on Robotics and Automation, pp. 122-127, 2002.

[22] P. Estevez, A. Mulder, and R. H. M. Schmidt, "6-DoF miniature maglev positioning stage for application in haptic micromanipulation," Mechatronics, vol. 22, no. 7, pp. 1015-1022, 2012.
[23] A. Hadi, A. Yousefi-Koma, M. M. Moghaddam, M. Elahinia, and A. Ghazavi, "Developing a novel SMA-actuated robotic module," Sensors and Actuators A: Physical, vol. 162, no. 1, pp. 72-81, 2010.

[24] G. Carbone, E. Daliesio, G. Borchert, and A. Raatz, "Design and validation of the binary actuated parallel manipulator BAPAMAN2," Advanced Robotics, vol. 27, no. 13, pp. 1033-1043, 2013.

[25] M. S. Mohamed Ali and K. Takahata, "Frequency-controlled wireless shape-memory-alloy microactuators integrated using an electroplating bonding process," Sensors and Actuators A: Physical, vol. 163, no. 1, pp. 363-372, 2010.

[26] M. Ali, A. AbuZaiter, C. Schlosser, B. Bycraft, and K. Takahata, "Wireless displacement sensing of micromachined spiral-coil actuator using resonant frequency tracking," Sensors, vol. 14, no. 7, pp. 12399-12409, 2014. 

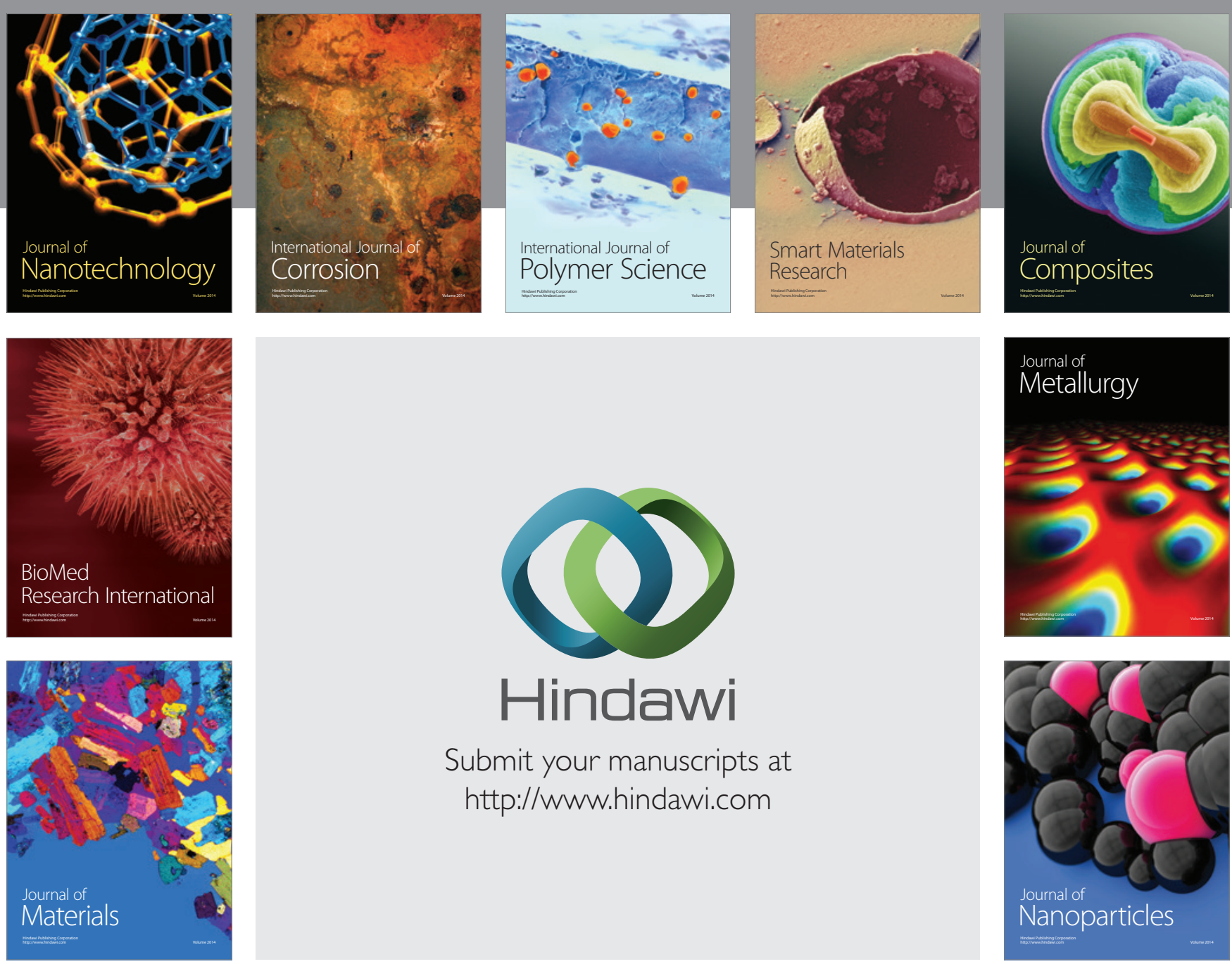

Submit your manuscripts at http://www.hindawi.com
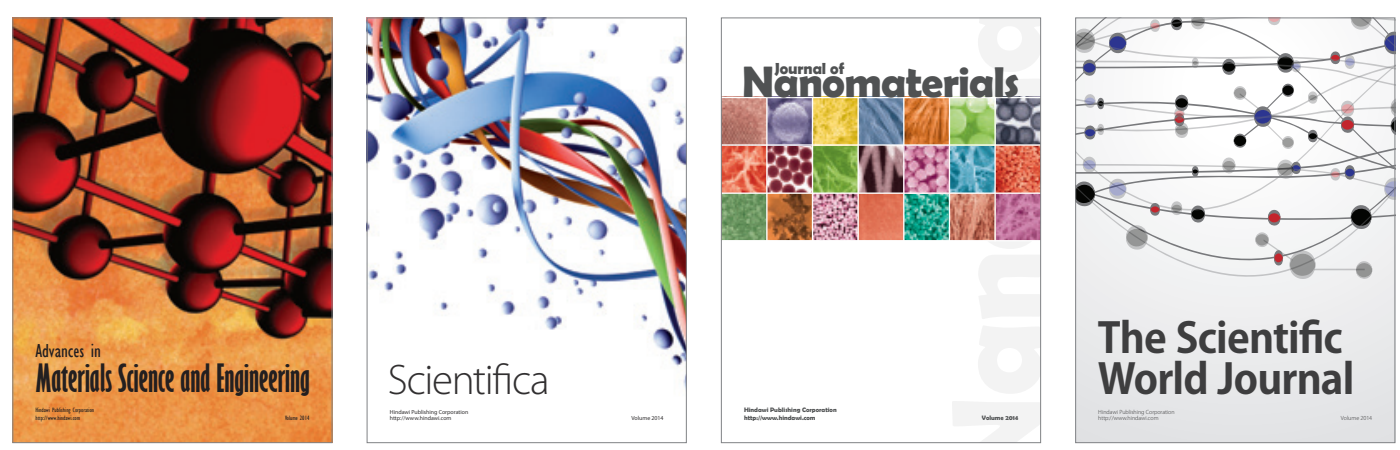

\section{The Scientific World Journal}
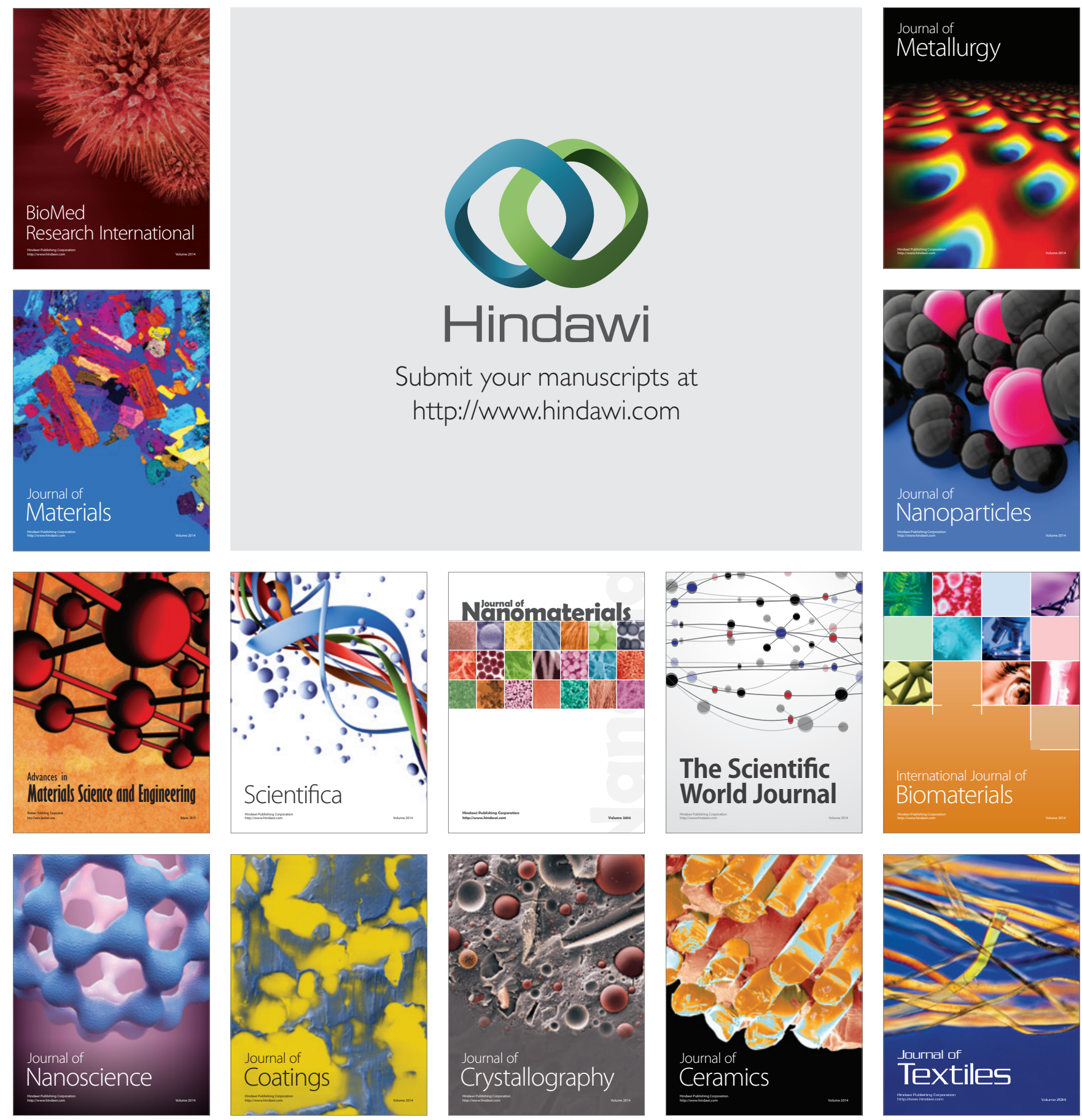